\title{
A rare case of placental site trophoblastic tumor
}

\author{
Shilpa Bajpai*, Prasad Lele
}

Department of Obstetrics and Gynaecology, Institute of Naval Medicine, INHS Asvini, Mumbai, Maharashtra, India

Received: 25 June 2021

Revised: 25 July 2021

Accepted: 26 July 2021

\author{
*Correspondence: \\ Dr. Shilpa Bajpai, \\ E-mail: drshilpa_afmc85@yahoo.co.in
}

Copyright: (C) the author(s), publisher and licensee Medip Academy. This is an open-access article distributed under the terms of the Creative Commons Attribution Non-Commercial License, which permits unrestricted non-commercial use, distribution, and reproduction in any medium, provided the original work is properly cited.

\begin{abstract}
Placental site trophoblastic tumor (PSTT) is a very rare tumor of young women and unique form of gestational trophoblastic disease (GTD) representing a neoplastic transformation of intermediate trophoblastic cells that play a critical role in implantation. It accounts for 1-2\% of all GTNs, incidence of it being 1 in 1,00,000 pregnancies. It displays a wide clinical spectrum from benign lesion within uterus to highly metastatic features with widespread features of metastasis and can be difficult to control even with surgery and chemotherapy. Unlike other forms of GTD, it is characterized by low $\beta$-hCG levels because it is a neoplastic proliferation of intermediate trophoblastic cells. PSTT can develop following all kind of pregnancies, whereas approximately 50\% of PSTT cases occur after a normal pregnancy and other cases follow abortion, term delivery, ectopic pregnancy and molar pregnancy. Histopathologically, PSTT has proliferation of intermediate trophoblastic cells and absence of villi. It shows less invasion of vascular tissue and using immune histochemistry revealed that PSTT cells expressed HPL more than $\beta$-hCG, characterized by increased expression of the HPL in histological section as well as serum. The most common presenting symptoms of PSTT are irregular vaginal bleeding associated with uterine sub involution. Patient can also be presented with amenorrhea, nephritic syndrome, abdominal pain, galactorrhea and hemoptysis. Hence any case of unusual bleeding should be investigated with dilation and curettage and $\beta \mathrm{HCG}$ levels. Although the majority of patients of the non-metastatic PSTT are cured by hysterectomy but in metastatic cases, it requires aggressive treatment with chemotherapy and radiation. Due to its seldom occurrence and uncharacteristic clinical presentation, to reach a correct diagnosis and management is a surgeon's nightmare and can be very challenging.
\end{abstract}

Keywords: GTD, PSTT, HPL

\section{INTRODUCTION}

PSTT is a rare type of gestational trophoblastic disease originating from the placental implantation site. ${ }^{1}$ It has gradually been acknowledged to feature both the benign and malignant potentials of this specific type of tumor. It differs from other GTD by a slow growth and a relative resistance to chemotherapy. The clinical features of PSTT are usually benign, but a few of them can relapse and metastasize, demonstrating the malignant biological behavior. The early diagnosis of PSTT remains uncertain, and it is difficult to distinguish the benign and malignant forms of PSTT in the early stage. ${ }^{2}$ The present obstacles in managing PSTT include malignancy prediction, fertility, preservation, recurrence and chemotherapy resistance and identification of possible treatment targets.

Here the authors presented a case of 30 years old parous lady who presented with irregular bleeding per vaginum on the 50th postnatal day. She was diagnosed as a case of PSTT following an array of investigations. The unusual presentation of patient leading to a conclusive diagnosis and following a systematic management protocol was creditable. Keeping in mind, her young age and future 
fertility, she was given a conservative treatment and we didn't jump to radical management opting conventional hysterectomy. The elaborated case report along with its review of literature was presented in consequent paragraphs below.

\section{CASE REPORT}

A 30 year old P2L2 lady presented with complaints of irregular bleeding per vaginum since 5 months. The last childbirth was 5 months back, wherein she underwent a full term normal delivery. There was no history of pain abdomen, mass palpable per abdomen, foul smelling discharge per vaginum.

On examination at our centre, she had BMI of $19.5 \mathrm{~kg} / \mathrm{m}^{2}$. Respiratory system, central nervous system and cardiovascular system examination were essentially normal. Abdomen was soft and non-tender.

On transvaginal sonography, a vascular intrauterine mass was seen, which looked like RPOC or a placental polyp.

For further confirmation, MRI was done where normal heterogeneous signal changes were observed in the wall of uterus in the T2-weighted image and enhanced heterogeneous tumor and parauterine tissue were seen after administration of contrast material, which further enhanced our suspicion of trophoblastic proliferation, as evident in Figure 1.

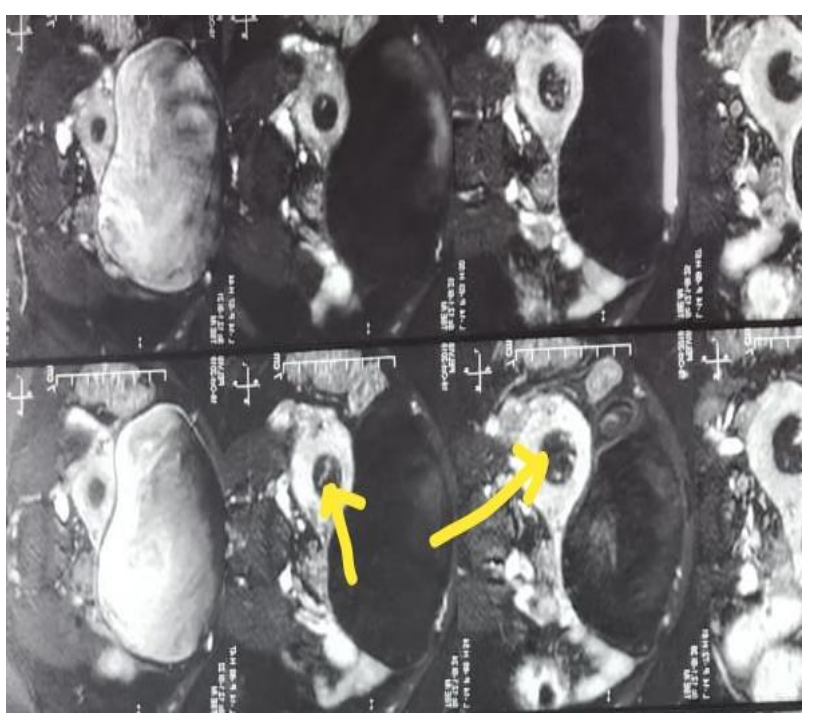

Figure 1: MRI pelvis showing the heterogeneous tumor in endometrium.

Her HPL values were $0.18 \mathrm{mcg} / \mathrm{ml}$ (normal values being 0.0-0.1 micrograms $/ \mathrm{ml}$ ) and $\beta-\mathrm{hCG}$ value was $6.0 \mathrm{mIU} / \mathrm{ml}$.

This patient was taken up for hysteroscopic guided endometrial biopsy and B/L uterine artery embolisation in the same sitting. Postoperatively the recovery was good and uneventful. The histopathology reported the tumor cells which were present in monomorphic population of large polyhedral cells with irregular hyperchromatic nuclei and were at different stages of mitosis. Besides this, there was eosinophilic or transparent substance in the cytoplasm, confirming our diagnosis of PSTT, as seen in Figure 2.

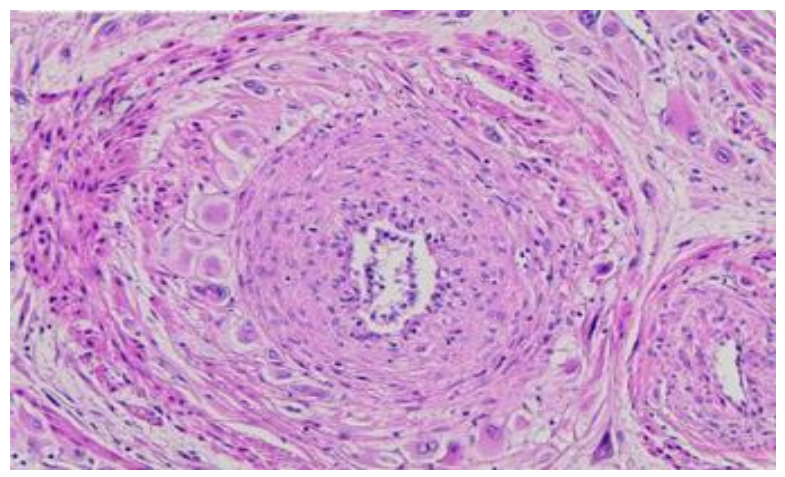

Figure 2: Large polyhedral cells with irregular hyperchromatic nuclei.

Keeping aside the conventional modalities of treatment we opted to preserve her uterus and kept her under follow up. The patient was advised and counselled for contraception and offered depot preparations of medroxy progesterone. Presently the patient showed no signs of recurrence.

\section{DISCUSSION}

The first case of PSTT was described in 1976 by Kurman and colleagues on a series of 12 cases, referred to as trophoblastic pseudo tumor, for a supposed benign pathology.

In 1981, Scully described the morphological details and recognized it as a neoplastic process and named it PSTT. In 1983, the WHO formally acknowledged the neoplastic nature of this lesion and adopted the terminology of PSTT. PSTT can occur following term labour, abortion and rarely in molar pregnancy. The interval from prior pregnancy to tumor development is usually less than 2 years, but a longer interval is also observed in some patients. Good prognosis is anticipated in cases localized to the uterus and when the interval between antecedent pregnancy and treatment is less than 2 years.

The standard and the conventional treatment remains surgery. The principle is to remove tumor and/or tumor involving organs, including total hysterectomy with or without bilateral salpingo-oophorectomy.

Huang et al also reported a case of 36 year old Chinese woman, 31 months following a prior normal pregnancy. ${ }^{3}$ The patient was successfully treated with hysterectomy with pre and postoperative chemotherapy. She showed no sign of recurrence with more than 3 years follow up. 
For patients with metastasis, it was believed that targeted surgery and high dose platinum-containing chemotherapy or etoposide are advisable treatment options.

Since most patients with PSTT are young women, the preservation of fertility during chemotherapy is a critical issue. At present, the means of conservation is mainly based on surgery and chemotherapy. The choice of surgical methods includes abdominal resection, laparoscopic resection and hysteroscopic resection. ${ }^{5-7}$ There was also report of using a modified Strausmann procedure (MSP) on suitable candidates. ${ }^{8}$ Some researchers have observed significant effects of arterial infusion of chemotherapy drugs, which significantly increased uterine preservation therapy. ${ }^{9}$

The success rate of fertility preservation treatment was relatively high in young women. However, a small number of patients who went through fertility preservation therapy eventually underwent hysterectomy, probably due to incomplete removal of residual lesions.

\section{CONCLUSION}

To summarize, PSTT is a type of trophoblastic neoplasm with very low incidence and benign characteristics. Similar to many other types of tumors, PSTT may be a result of comprehensive interaction between genetic, immunological and environmental factors. The prognosis of most PSTT cases is desirable; however, metastasis or recurrence occurs in a few cases. Most PSTT patients are young women hence fertility preservation is an important consideration. The obstacle of fertility-preserving treatment lies in the establishment of criteria to distinguish patients that are suitable to preserve fertility. Scholars have proposed appropriate conditions for fertility preservation, those factors include stage 1, >35 years old, a strong fertility requirement, acceptable chemotherapy responsiveness, no malignant prognostic factors such as deep myometrium infiltration. The prognosis of most PSTT cases is desirable; however, metastasis or recurrence does occur.
Funding: No funding sources Conflict of interest: None declared Ethical approval: Not required

\section{REFERENCES}

1. Kurman RJ, Scully RE, Norris HJ. Trophoblastic pseudotumor of the uterus: an exaggerated form of "syncytial endometritis" simulating a malignant tumor. Cancer. 1976;38(3):1214-26.

2. Braga A, Mora P, Melo ACD, Nogueira-Rodrigues A, Amim-Junior J, Rezende-Filho J, et al. Challenges in the diagnosis and treatment of gestational trophoblastic neoplasia worldwide. World J Clin Oncol. 2019;10(2):28-37.

3. Huang F, Zheng W, Liang Q, Yin T. Diagnosis and treatment of placental site trophoblastic tumor. Int $\mathbf{J}$ Clin Exp Pathol. 2013;6(7):1448-51

4. Jean BDLJ, Khomsi F, Anis F, Nordine BA, JeanBernard D, Ani F. Placental site trophoblastic tumor: a case report and review of the literature. Front Surg. 2014;1:31.

5. Zhao J, Lv WG, Feng FZ, Wan XR, Liu JH, Yi XF, et al. Placental site trophoblastic tumor: a review of 108 cases and their implications for prognosis and treatment. Gynecol Oncol. 2016;142(1):102-8.

6. Tsuji Y, Tsubamoto H, Hori M, Ogasawara T, Koyama K. Case of PSTT treated with chemotherapy followed by open uterine tumor resection to preserve fertility. Gynecol Oncol. 2002;87(3):303-7.

7. Chiofalo B, Palmara V, Lagana AS, Triolo O, Vitale SG, Conway F, et al. Fertility sparing strategies in patients affected by placental site trophoblastic tumor. Curr Treat Options Oncol. 2017;18(10):58.

8. Saso S, Haddad J, Ellis P, Lindsay I, Sebire NJ, McIndoe A, et al. Placental site trophoblastic tumours and the concept of fertility preservation. BJOG. 2012;119(3):369-74.

9. Schmid P, Nagai Y, Agarwal R, Hancock B, Savage PM, Sebire NJ, et al. Prognostic markers and longterm outcome of placental-site trophoblastic tumours: a retrospective observational study. Lancet. 2009;374(9683):48-55.

Cite this article as: Bajpai $\mathrm{S}$, Lele $\mathrm{P}$. A rare case of placental site trophoblastic tumor. Int J Reprod Contracept Obstet Gynecol 2021;10:3594-6. 